\title{
Modelling of Stator Coil-To-Ground Faults in Induction Motor
}

\author{
Stanislav Kocman, Pavel Pečínka \\ ${ }^{1}$ Department of General Electrical Engineering \\ VŠB - Technical University of Ostrava \\ Ostrava, Czech Republic \\ Phone: +420 597325 922, +420 732388375 e-mail: stanislav.kocman@vsb.cz, pavel.pecinka.st@vsb.cz
}

\begin{abstract}
Three-phase squirrel cage induction motors are the most widespread types of electrical motors which can be found in both industrial and tertiary applications. There are some reasons why they are so often used, such as simple construction, nearly maintenance-free, advantageous price and the possibility to feed them directly from the AC network. Even if their reliability is very high, some unexpected breakdowns can occur during their operation. In this paper, coil-to-ground faults of motor stator winding have been taken into consideration. These failures have been modelled in several points of one stator phase using COMSOL software. As seen from simulation results these failures have a significant impact on current distribution in stator phases causing changes in rotor currents, motor inner torque, speed, etc., depending strongly on the actual point of the failure.
\end{abstract}

Key words. Induction motor, model, simulation, stator currents, stator faults

\section{Introduction}

Electrical motors are in common use in various electrical drives, both non-adjustable and adjustable (pumps, compressors, fans, conveyors, machine tools, cranes, lifts, mills, reeling machines...). The electrical drive, and its motor, is an important part of various technologies, whose reliability has an important influence on the reliability of the whole technology. From this reason three-phase squirrel cage motor is very often used due to its high level of reliability. Despite this fact, some internal and external factors can lead to internal effects in the induction motor causing its malfunction with consequences on production losses, breakdown or potential destruction of devices in the system, and safety. Therefore, motor monitoring, regular maintenance and diagnostics are very important [1]-[4].

There are different types of failures of induction motors in electrical drive systems. These failures can include electrical faults, mainly stator and rotor winding open or short circuited caused by a failure in power supply or failures of motor insulation, power quality problems affecting motor behavior, broken rotor bars and end-rings of squirrel cage motor, and mechanical faults including rotor touch on stator, bearing and fan failures or bent shaft [5]-[6]. According to several studies the most common faults are stator winding failures, which account for $35-40 \%$ of the total induction motor breakdowns, and bearing failures (around $40 \%$ of motor breakdowns) [7]-[8].

The stator winding faults are associated with the stator winding insulation breakdowns [9]. In this paper, one phase to ground fault is under consideration and studied in various points of failure of the affected phase as seen in Fig. 1. These failures cause current unbalance resulting in high current in the affected phase with an influence on currents in the remaining phases. The current unbalance is accompanied by changes of motor parameters and by thermal stresses responsible for the degradation of the stator winding insulation and electrodynamic stresses with an impact on end winding bonding and stator wedging deteriorating the reliability of the motor.

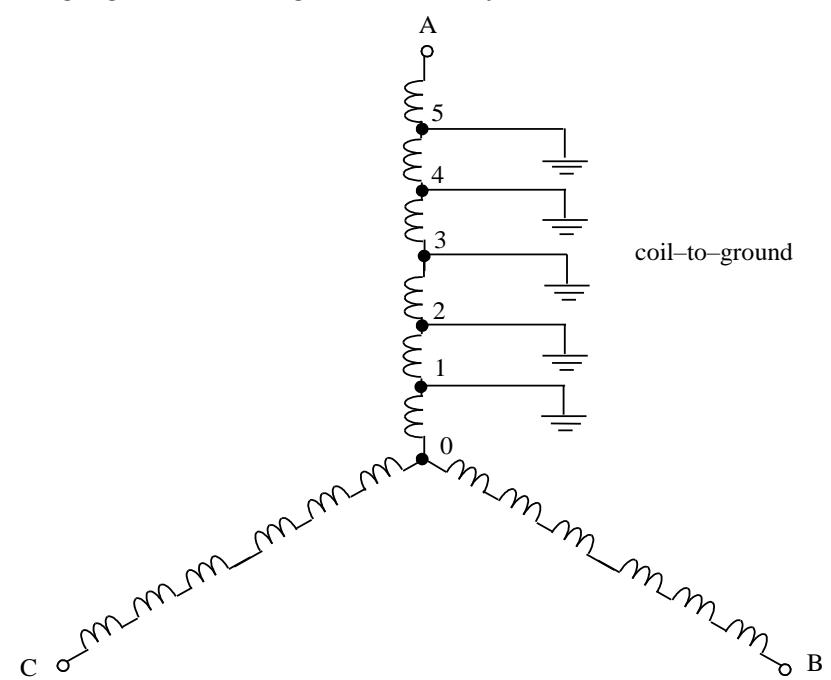

Fig. 1. Stator winding fault (coil-to-ground)

\section{Mathematical model of induction motor}

Induction motor is rather complex three-phase non-linear system. To reduce the number of phases some transformations are used. In this case, Clarke's transformation is applied which converts three-phase balanced system into two-phase stator-fixed system. This transformation is useful for a study of stator quantities. The main assumption for the mathematical model is that the resultant magnetic field in the machine is spatially sinusoidal as a result of sinusoidal magnetic fields of three stator windings, which are spatially phase-shifted by $120^{\circ}$. The sinusoidal functions make the machine modelling analytically tractable. To build motor mathematical model so some simplifying assumptions are accepted, namely sinusoidal, balanced currents, neglected stator and rotor slotting effects, no losses linear material of motor iron, spatially symmetrical distributed windings, equal resistances and inductances in each phase, constant 
machine air-gap. The basic differential equations for the mathematical model can be found e.g. in [10]-[11]. In the stator coordinate system, the voltage equation is for one phase as follows:

$$
v_{S}=R_{S} i_{S}+\frac{d \psi_{S}}{d t},
$$

where $v_{S}$ is the stator voltage spatial vector, $\boldsymbol{i}_{\mathrm{S}}$ is the stator current, $R_{S}$ is the stator resistance, $\psi_{S}$ is the stator flux linkage.

In the rotor coordinate system, the voltage equation is for one phase as follows:

$$
\boldsymbol{v}_{R}=R_{R} i_{R}+\frac{d \boldsymbol{\psi}_{R}}{d t},
$$

where $\boldsymbol{v}_{R}$ is the rotor voltage spatial vector, $\boldsymbol{i}_{\mathrm{R}}$ is the rotor current, $R_{R}$ is the rotor resistance, $\psi_{R}$ is the rotor flux linkage. The flux linkages in (1) and in (2), respectively, are defined as:

$$
\begin{aligned}
& \boldsymbol{\psi}_{S}=L_{S} \boldsymbol{i}_{S}+L_{m} \boldsymbol{i}_{R} e^{\mathrm{j} \omega t}, \\
& \boldsymbol{\psi}_{R}=L_{R} \boldsymbol{i}_{R}+L_{m} \boldsymbol{i}_{S} e^{\mathrm{j} \omega t},
\end{aligned}
$$

where $L_{S}$ is the total stator inductance depending on selfinductance of the phase and mutual inductance of stator phases, $L_{m}$ is the mutual inductance of stator and rotor, $\omega$ is the rotor angular velocity, $L_{R}$ is the total rotor inductance depending on self-inductance of the phase and mutual inductance of rotor phases.

These equations compose the basic equations for induction motor. Motor inner electromagnetic torque is defined as:

$$
\begin{aligned}
& \tau=\frac{3}{2} p \mathrm{I}_{\mathrm{m}}\left\{\boldsymbol{i}_{S} \boldsymbol{\psi}_{S}^{*}\right\}, \\
& \tau=J \frac{d \omega}{d t}+\tau_{L},
\end{aligned}
$$

where $p$ is the number of the pole pairs, $J$ is the moment of inertia, $\omega$ is the rotor angular velocity, $\tau_{L}$ is the load torque. The equations are written in the nature reference frame. To have the mathematical model simpler, the transformations are used, which convert the three-phase system into twophase system. By means of them, the coordinate system can be fixed to stator, or to rotor, and or the coordinates are rotating with the synchronous speed [10].

As seen from the equations, there is the coupling between the currents in the motor windings and flux linkages. A fault in one stator phase leads to a current unbalance in the winding resulting in a change of flux linkages in the machine causing changes of currents in remaining health phases. This current unbalance can be significant with negative effects on the machine. These changes bring a change of motor inner electromagnetic torque with an impact on motor mechanical speed. These impacts were studied and some results are shown in this paper.

\section{Simulation model of induction motor}

The catalogue parameters of the tested induction motor are shown in Table I.
Table I. - The selected parameters of motor

\begin{tabular}{|c|c|c|c|}
\hline Parameter & Value & Parameter & Value \\
\hline Rated power & $4 \mathrm{~kW}$ & $\begin{array}{c}\text { Nom. power } \\
\text { factor }\end{array}$ & 0.83 \\
\hline Nominal voltage & $400 \mathrm{~V}$ & $\begin{array}{c}\text { Nominal } \\
\text { speed }\end{array}$ & $1440 \mathrm{rpm}$ \\
\hline Nominal current & $8.4 \mathrm{~A}$ & $\begin{array}{c}\text { Nominal } \\
\text { torque }\end{array}$ & $27 \mathrm{~N} \cdot \mathrm{m}$ \\
\hline $\begin{array}{c}\text { Nominal } \\
\text { frequency }\end{array}$ & $50 \mathrm{~Hz}$ & $\begin{array}{c}\text { Nominal } \\
\text { efficiency }\end{array}$ & $83.1 \%$ \\
\hline
\end{tabular}

COMSOL Multiphysics software was used for simulations of coil-to-ground faults of motor stator winding. The created model of the tested motor was verified to ensure that the implementations of the model is correct for studies of motor failures or anomalies. Simulations of motor nominal operating conditions, under no-load and under locked rotor, and of motor startup, respectively, were carried out before this testing.

The model was designed as two-dimensional one with defined out of plane thickness [12]-[14]. The modelling of the motor requires precise layout of motor geometry, accurate material properties and values of components of electrical circuits representing overhang effects.

To feed the motor model from three-phase balanced sinusoidal voltage source of nominal RMS values and frequency, the Electrical Circuit interface of COMSOL is used, which includes connections to the COMSOL Rotating Machinery, Magnetic interface, and components to represent end winding impedances. This interface is also used for a design of the external rotor circuit. The equations used for calculations of the values of components in the external stator and rotor electrical circuits are in [15].

The Rotating Machinery, Magnetic interface under the AC/DC Module of COMSOL is used for stationary and time-domain modelling of the motor.

Starting induction motor in a drive assembly is a transient process, which is described by the fundamental torque equation, or the equation of motion, as defined by (6). To simulate the motor start-up the modified motion equation is used in the Global ODEs and DAEs interface of COMSOL formulated as:

$$
\tau=J \frac{\mathrm{d}^{2} \alpha}{\mathrm{d} t^{2}}+\tau_{L},
$$

where $\alpha$ is the rotation angle.

The designed model is used for various studies of the tested motor under electrical or mechanical faults or anomalies. The aim of this paper is study of an influence of the point of coil-to-ground fault on values of stator currents and their distribution in phases, on values and waveforms of inner electromagnetic torque and mechanical speed, and on the magnetic flux density distribution in the machine. As seen in Fig. 1 the failure points are assumed in five points regularly distributed in one phase. The point marked as 0 (the node) means the failure-free operation for the simulation. 


\section{Simulation results}

The simulations have been carried out for the motor loaded with the nominal torque equal to $27 \mathrm{~N} \cdot \mathrm{m}$. The direct online start-up has been modelled for each example of stator winding fault as shown in Fig. 1. The start-up transient is fast and accompanied by high starting currents, and oscillations in the motor inner torque, which are given by behavior of the model in COMSOL software. These oscillations correspond to the oscillations of the currents in the rotor bars and rings, and in motor speed. Stator currents are shown in Fig. 2, motor inner torque in Fig. 3 and motor speed in Fig. 4. As can be seen from the simulated waveforms of stator currents, torque or speed the motor reaches its steady-state after time equal to $\mathrm{c}$. $0.35 \mathrm{~s}$. After this time, the motor reaches its steady-state speed equal to $1437.8 \mathrm{rpm}$, which is very close to its nominal value in Table I. In Fig. 5, the induction motor geometry is shown illustrating the magnetic flux density distribution and equipotential lines of the magnetic vector potential before the stator fault. As seen the magnetic field is symmetrical and creates four magnetic poles.

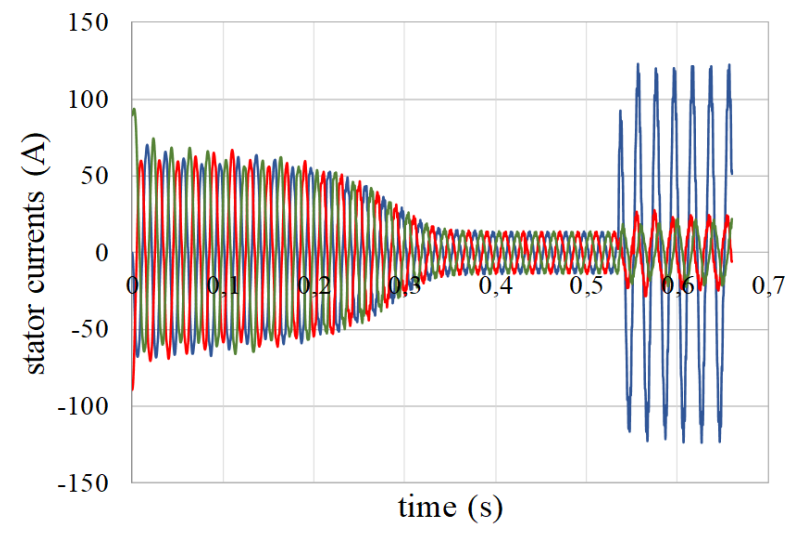

Fig. 2. Waveforms of stator currents

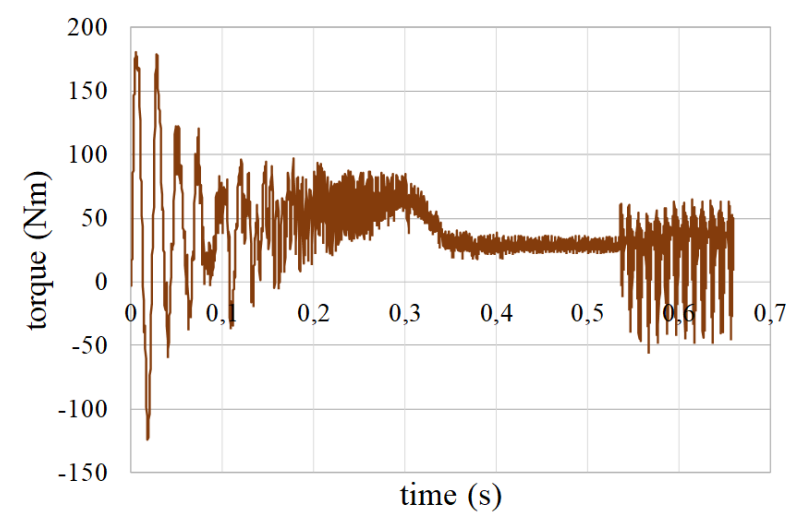

Fig. 3. Waveform of inner torque

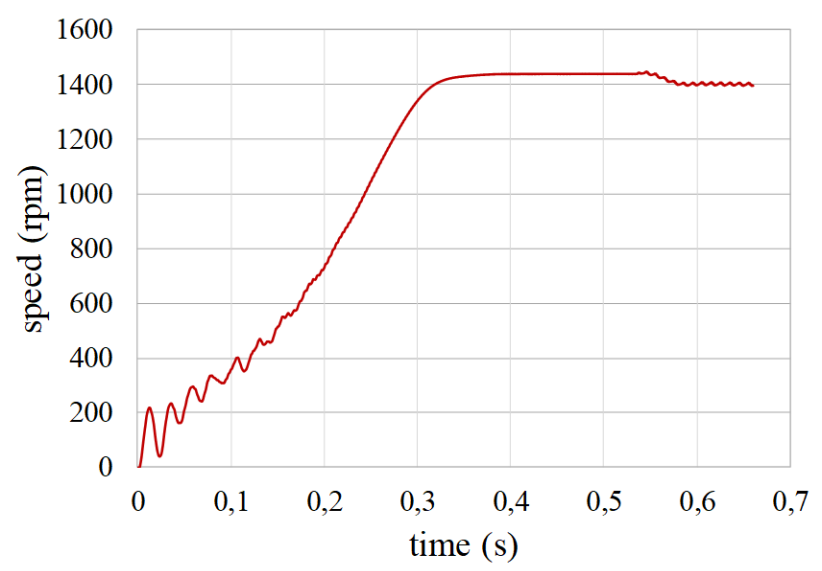

Fig. 4. Waveform of speed

The moment of inertia of no-loaded drive assembly equal to $0,05 \mathrm{kgm}^{2}$ was adjusted into COMSOL. This motor cannot be connected directly to the mains. The starting time under no-load detected from the experimental measurement is comparable to the starting time detected from the waveforms simulated in COMSOL [16].

I this case, the induction motor draws from the threephase voltage source three-phase currents whose the first harmonics are shown in Fig. 6. As seen the currents are balanced with identical peak values and with phase shifts equal to $120^{\circ}$. Such balanced system creates the symmetrical magnetic field in the machine as seen in Fig. 5.

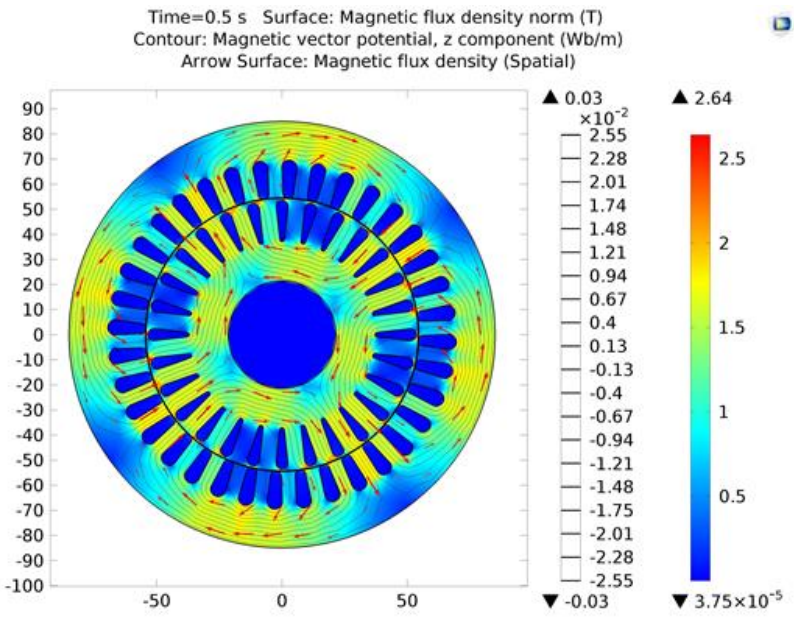

Fig. 5. Magnetic flux density and equipotential lines of magnetic vector potential of healthy motor 


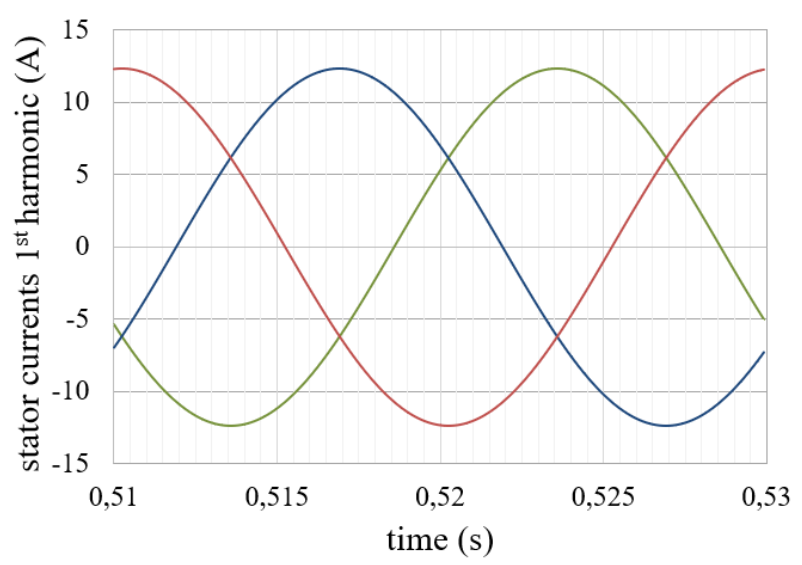

Fig. 6. Waveforms of stator currents $1^{\text {st }}$ harmonic at steady-state operation before the coil-to-ground short failure

After reaching the steady-state a coil-to-ground short emerges in one phase of the stator winding with consequences for the monitored quantities as seen in Fig. 2, Fig. 3, and Fig. 4, respectively. In this case, the failure is modeled in the point 3 in Fig. 1. The failure causes very high unbalance of stator currents both amplitude and phase. The current amplitude in the affected phase reaches much higher value than in the remaining ones, however, in which their amplitudes are also above the level of nominal values. This high current unbalance affects magnetic field conditions in the machine with effects on motor quantities, such as inner torque and speed as it can be seen in Fig. 3, and in Fig. 4, respectively. High oscillations are present in the inner torque, which are associated with the high unbalanced stator currents. The induction motor speed is also affected when its oscillations correspond to them in the inner torque, and slows down.

The impact of coil-to-ground failure in points 1, 3 and 5 of the stator phase in Fig. 1 on magnetic field distribution in motor and on distribution of stator currents is shown in Fig. 7, Fig. 8, Fig. 9, Fig. 10, Fig. 11 and Fig. 12.

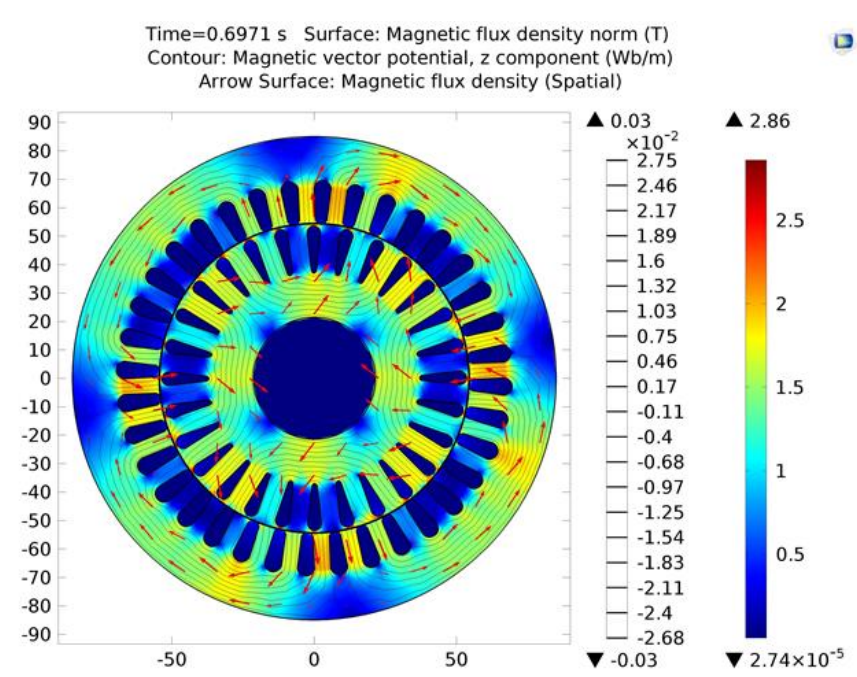

Fig. 7. Magnetic flux density and equipotential lines of magnetic vector potential of motor under coil-to-ground failure in point 1

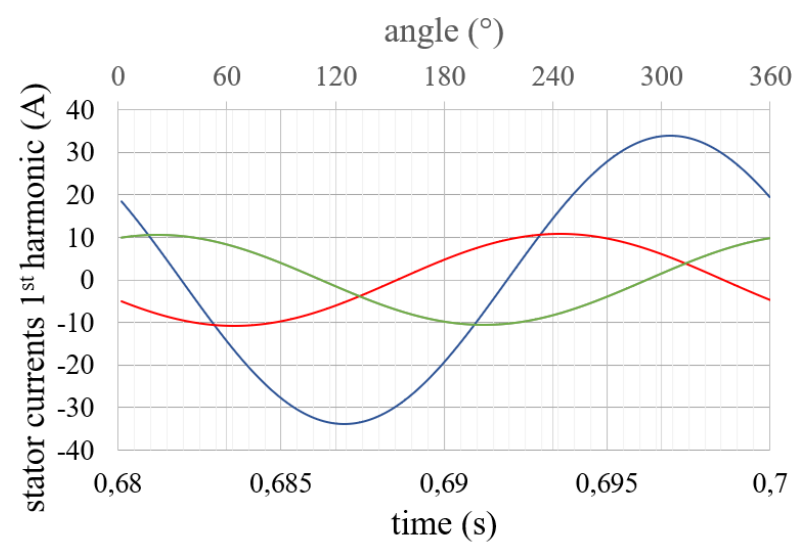

Fig. 8. Waveforms of stator currents $1^{\text {st }}$ harmonic under coilto-ground failure in point 1

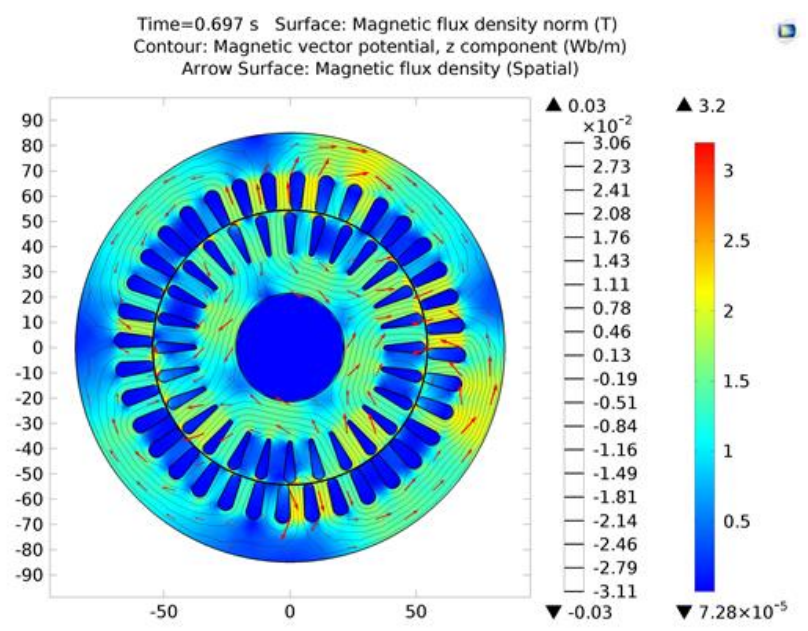

Fig. 9. Magnetic flux density and equipotential lines of magnetic vector potential of motor under coil-to-ground failure in point 3

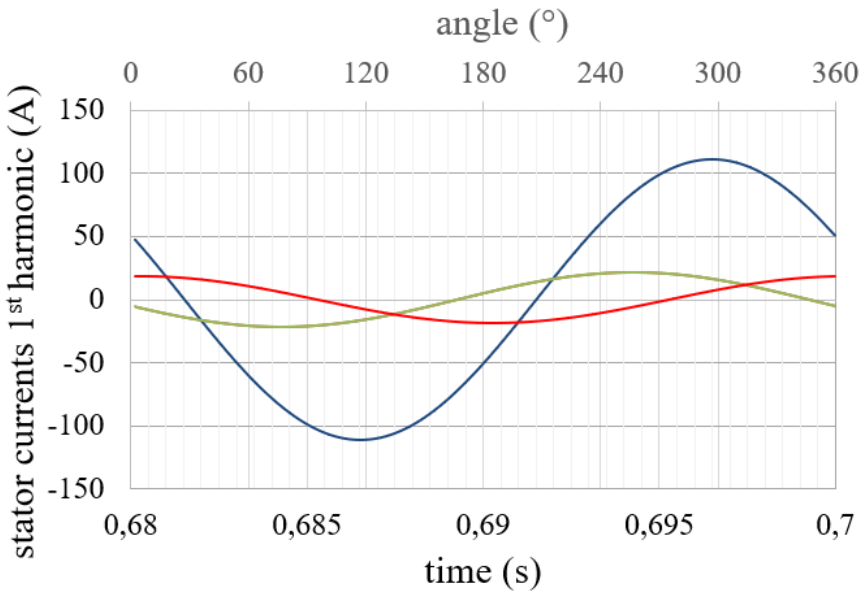

Fig. 10. Waveforms of stator currents $1^{\text {st }}$ harmonic under coilto-ground failure in point 3 


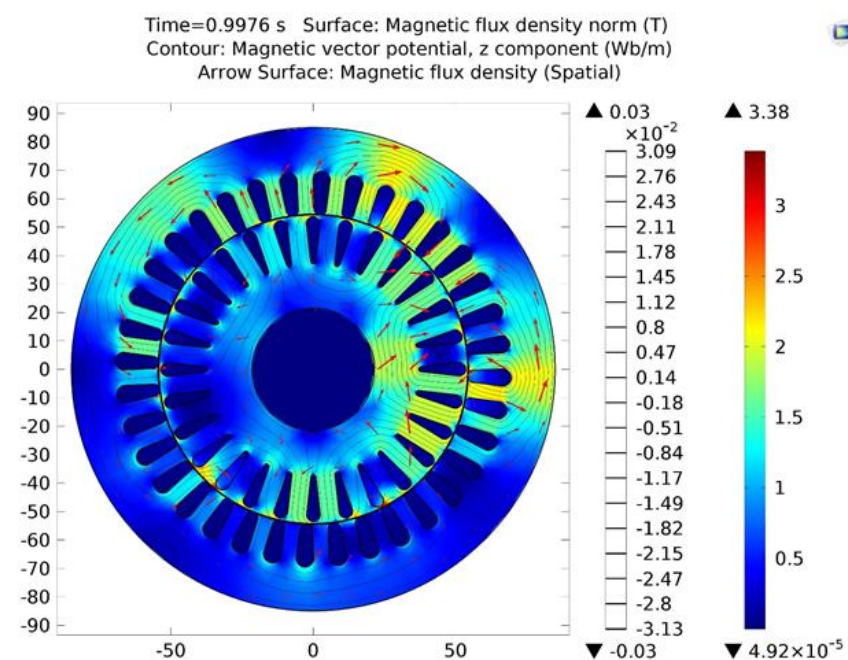

Fig. 11. Magnetic flux density and equipotential lines of magnetic vector potential of motor under coil-to-ground failure in point 5

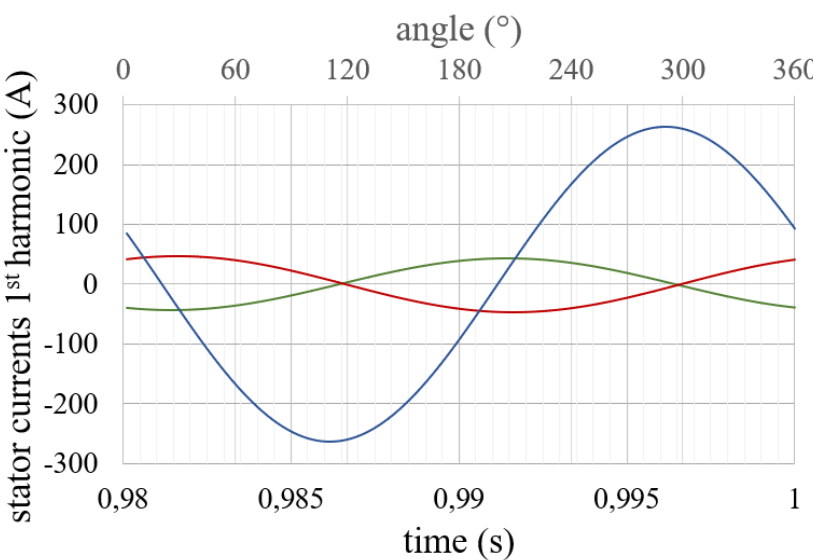

Fig. 12. Waveforms of stator currents $1^{\text {st }}$ harmonic under coil-toground failure in point 5

As seen, the failures have high impact on values of currents and their phases in stator winding. As regards the failure in point 1 , that means close to the node, it causes high current unbalance as shown in Fig. 8. The current in the affected phase drawn from the source reaches the RMS value above the nominal one (24 A), whereas in the remaining ones they are below it, namely 7,7 $\mathrm{A}$ and 7,5 $\mathrm{A}$. High level of phase unbalance can be also seen in Fig. 8 when phase shifts between two phases are equal to $61^{0}$, $222^{\circ}$ and $77^{\circ}$. This condition affects the magnetic field distribution in motor, which is not symmetrical anymore, but with a certain level of asymmetry, as seen in Fig. 7. The values of magnetic flux density in some parts of stator and rotor sheets are increased in comparison to the condition under the balanced currents. The coil-to-ground faults in point 3 , and in point 5 , respectively, cause very high current unbalances as seen in Fig. 10 and in Fig. 12. Their consequences for the magnetic field in motor are shown in Fig. 9 and in Fig. 11. Namely for the coil-toground short in point 5 when the very high drawn current reaching its value of $185 \mathrm{~A}$ in the affected phase causes very high asymmetry of the motor magnetic field.

With a shift of the failure point towards the source, the unbalance of drawn currents rises up to its peak value at point 4, after it slightly drops as it can be seen in Fig. 13. a A distribution of the drawn current first harmonics is shown in Fig. 14 for each phase, and at each studied point. As seen, the value of input current in the affected phase rises very fast, which corresponds to peak values in Fig. 6, Fig. 8, Fig. 10, and Fig. 12, respectively.

As mentioned above, the stator current unbalance affects the distribution of magnetic field in stator and rotor sheets, which has an influence on induced voltage and current in rotor circuit with consequences on a course of motor inner torque. Even if there are small oscillations in the inner torque under the balanced condition, these are much amplified by the unbalanced currents, as seen in Fig. 3. The detailed course of the motor inner torque after the coil-to-ground short is presented in [17]. However, this very rippled course does not cause an increasing its mean value, which can be seen in Fig. 15. This mean value corresponds to the value of load torque of $27 \mathrm{~N} \cdot \mathrm{m}$ setting in COMSOL, and which is equal to the motor nominal torque shown in Table I.

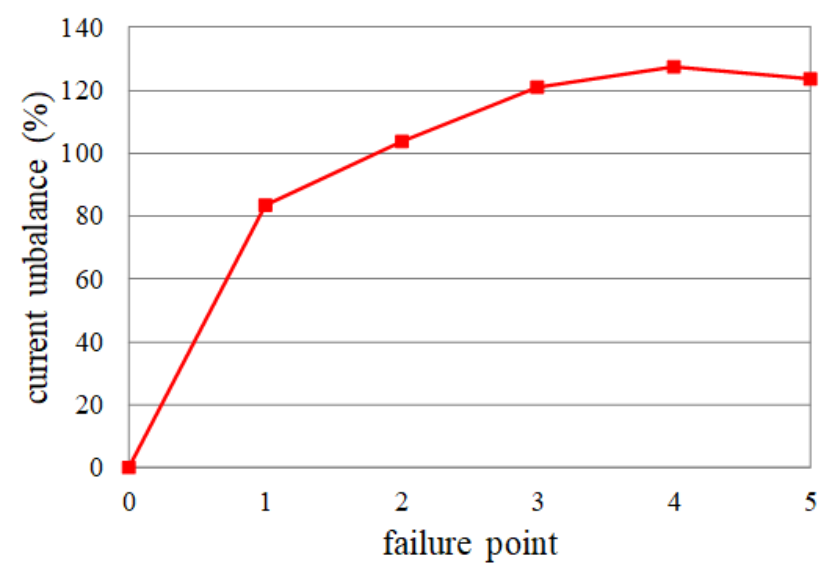

Fig. 13. Current unbalance for tested failure points

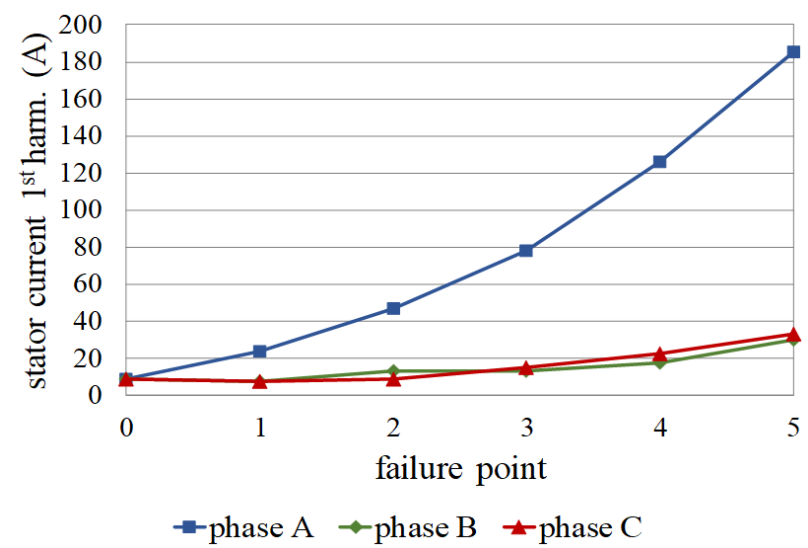

Fig. 14. Stator current $1^{\text {st }}$ harmonics for tested failure points 


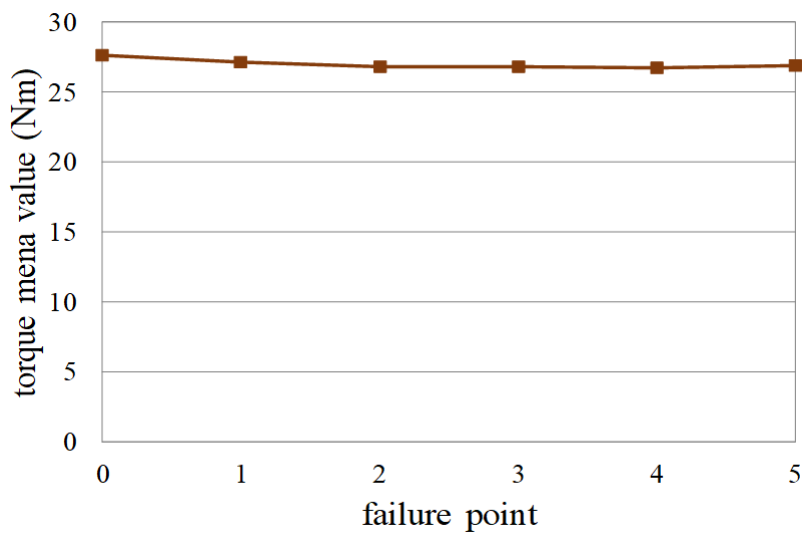

Fig. 15. Inner torque mean value for tested failure points

The high oscillations in motor inner torque after the fault cause oscillations in the course of motor speed, and what is more, a drop of the speed to a new steady-state value in connection to the current unbalance and rotating magnetic field change. It can be seen in Fig. 4 for the case of coilto-ground failure in point 3 . A dependence of mean value of speed on the failure point is shown in Fig. 16.

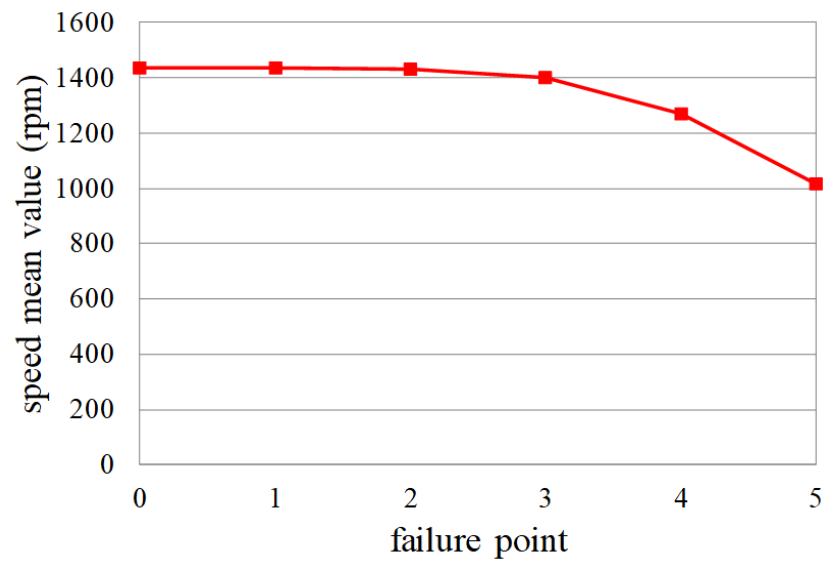

Fig. 16. Speed mean value for tested failure points

\section{Conclusion}

The simulations of the stator coil-to-ground faults have been carried out for several points of one phase to show the dependence of observed motor parameters on the actual point of failure. As seen from the presented results, the current in the affected phase, magnetic field distribution in motor, waveforms of currents, inner torque and speed are strongly dependent on the failure point. The mechanical load of motor is assumed to be constant and equal to the nominal one. In each tested failure point, the current of affected phase exceeds its nominal value, and it is fast-growing when the failure point shifts towards the terminal with harmful consequences for machine.

\section{References}

[1] Y. B. Koca, and A. Unsal, "A rewiev on detection and monitoring of stator faults of induction motors," International Journal of Innovative Research in Science, Engineering and Technology, vol. 6, iss. 10, pp. 70-74, May 2017.

[2] S. Karmakar, S. Chattopadhyay, M. Mitra, and S. Sengupta, Induction Motor Fault Diagnosis. Singapore: Springer-Verlag, 2016, pp.7-28.

[3] A. Ukil, S. Chen, and A. Andenna, "Detection of stator short circuit faults in three-phase induction motors using motor current zero crossing instants," Electric Power Systems Research, No. 81, vol. 4, pp. 1036-1044, April 2011.

[4] H. Guzman, I. Gonzalez, F. Barrero, and M. Durán, Induction Motors - Applications, Control and Fault Diagnostics. London: IntechOpen, 2015.

[5] K.K. Pandey, P.H. Zope, and S.R. Suralkar, "Review on fault diagnosis in three-phase induction motor," International Journal of Computer Applications, vol. 1, pp. 53-58, Sep. 2012.

[6] L. Varshney, S. Jovanovic, J.S. Shakya, and R.K. Saket, "Performance and reliability evaluation of induction machines: an overview," International Journal of Research and Review in Applied Sciences, vol. 8, No. 1, pp. 104108, Jul. 2011.

[7] S.M.Shashidhara, "Stator winding fault diagnosis of induction motor using FFT," International Journal of Advance Engineering and Research Development, vol. 4, iss. 10, pp. 816-826, Oct. 2017.

[8] A. A. Obed, "Detection, protection from, classification, and monitoring electrical faults in 3-phase induction motor based on discrete S-transform," International Journal of Applied Engineering Research, vol. 13, iss. 9, pp. 66906699, 2018.

[9] P. Kadaník, O. Červinka, and J. Ryba, Causal Model of Induction Motor for Stator Diagnostics. Rockwell Automation, Prague, 2000.

[10] E. Thoendel, Simulační model asynchronního stroje, FEL ČVUT Praha, 2008.

[11] M. Konuhova, G. Orlovskis, K. Ketners, "Mathematical modelling of induction motor transient processes during stator winding interruption," Scientific Journal of Riga Technical University, vol. 27, pp. 73-76, 2010.

[12] J. Martinez, A. Belahcen, and A. Arkkio, "A 2D FEM model for transient and fault analysis of induction machines," Przeglad Elektrotechniczny, vol. 88, No. 7B, pp. 157-160, Jul. 2012.

[13] V. N. Savov, Zh. D. Georgiev, and E. S. Bogdanov, "Analysis of cage induction motor by means of the finite element method and coupled system of field, circuit and motion equations," Electrical Engineering, vol. 80, pp. 2128, Feb. 1997.

[14] S. Kocman, P. Pečínka, and T. Hrubý, "Induction motor modelling using COMSOL Multiphysics," 17th International Scientific Conference on Electric Power Engineering, Prague, pp. 408-412, May 2016.

[15] S. Kocman, T. Hrubý, P. Pečínka, and A. Neumann, "FEM model of asynchronous motor for analysis of its parameters, “ 11th IEEE International Conference ELEKTRO, Strbske Pleso, pp. 315-319, Sep. 2016.

[16] S. Kocman, P. Orság, P Pečínka, "Simulation of start-Up behaviour of induction motor with direct online connection", Advances in Electrical and Electronic Engineering. vol. 15, pp 754-762, Dec. 2017.

[17] S. Kocman, and S. Nowak, "Analysis of the stator winding fault of induction motor using COMSOL multiphysics," 20th International Scientific Conference on Electric Power Engineering, Kouty nad Desnou, pp. 290-295, May 2019. 